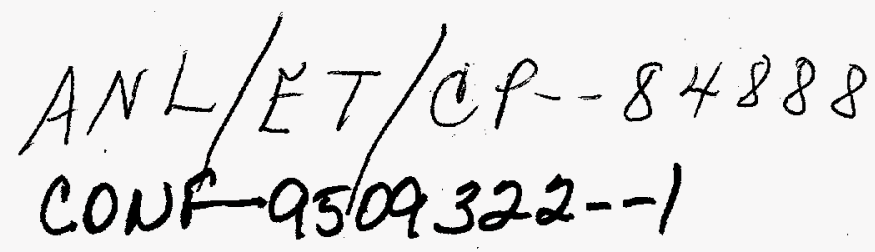

\title{
Flow Visualization of Microscale Thermal Mechanics of Boiling in Small Channels*
}

\author{
by \\ K. E. Kasza \\ M. W. Wambsganss \\ Argonne National Laboratory \\ Energy Technology Division, Bldg. 335 \\ 9700 S. Cass Ave. \\ Argonne Illinois 60439
}

\begin{abstract}
The submitted manuscript has been authored by a contractor of the U. S. Government under contract No. W-31-109ENG-38. Accordingly, the U. S. Government retains a nonexclusive, royalty-free license to publish or reproduce the published form of this contribution, or allow others to do so, tor U.S. Government purposes.
\end{abstract}

\section{DISCLAIMER}

\begin{abstract}
This report was prepared as an account of work sponsored by an agency of the United States Government. Neither the United States Government nor any agency thereof, nor any of their employees, makes any warranty, express or implied, or assumes any legal liability or responsibility for the accuracy, completeness, or usefulness of any information, apparatus, product, or process disclosed, or represents that its use would not infringe privately owned rights. Reference herein to any specific commercial product, process, or service by trade name, trademark, manufacturer, or otherwise does not necessarily constitute or imply its endorsement, recommendation, or favoring by the United States Government or any agency thereof. The views and opinions of authors expressed herein do not necessarily state or reflect those of the United States Government or any agency thereof.
\end{abstract}

Submitted for presentation at 7 th International Symposium on Flow Visualization, Seattle, Washington, September 1995.

*Work supported by the U.S. Department of Energy, Office of Energy Efficiency and Renewable Energy, under Contract W-31-109-Eng-38. 
DISCLAIMER

Portions of this document may be illegible in electronic image products. Images are produced from the best available original document. 


\author{
Abstract \\ Submitted for presentation at \\ 7th International Symposium on Flow Visualization \\ Seattle, Washington \\ September 1995
}

Flow Visualization of Microscale Thermal Mechanics

of Boiling in Small Channels

by

K. E. Kasza*

M. W. Wambsganss

Argonne National Laboratory

Energy Technology Division, Bldg. 335

9700 S. Cass Ave.

Argonne Illinois 60439

This paper describes the use of flow visualization via ultra-high-speed video and microscope optics to study the microscale thermal mechanics of boiling in small channels. The results presented here are for boiling water in a small rectangular channel. Because of confinement effects, flow regimes that occur in small channels are considerably different than those in large channels.

\title{
Background
}

Today there is worldwide interest in compact heat exchangers of the plate-fin, laminar, and microchannel types (Shah 1991). Advanced manufacturing methods and materials, as highlighted by Reay (1988), have surpassed our ability to design an optimal heat transfer surface for a given heat duty. For example, designers may know from trial and error that a particular channel geometry and size improves boiling heat transfer, but they generally do not understand the basic mechanisms involved and therefore are not able to optimize their designs or extrapolate with confidence to a hybrid design. Research is needed to address the fundamental issues associated with multiphase flow and heat transfer in small channels. The work described in this paper directly addresses this need.

Boiling heat transfer data from small, electrically heated, nontransparent, metal channels shows that for channel cross-sectional sizes of less than about $3 \mathrm{~mm}$, heat transfer behavior considerably different from that in larger tubes occurs (Wambsganss et al. 1993, 1994; Tran et al. 1994). Several physical mechanisms that are potentially dominant in small channels but are of lesser importance in large channels have been identified. Of major importance is that vapor bubbles generated by wall boiling in several refrigerants and water, and probably in other liquids as well, can be nominally the same size as the channel cross-sectional dimensions in compact heat exchangers, when the dimensions are nominally $3 \mathrm{~mm}$ or less (Kasza and Wambsganss 1994). Hence, it is believed that bubblegrowth processes, together with bubble/bubble and bubble/channel wall interactions, can result in vigorous mixing and disruption of the confined channel flow, in turn causing small-channel boiling to exhibit different behavior than that in large tubes. To study these mechanisms more thoroughly, a test apparatus employing extensive use of flow visualization has been built. Data from this apparatus are being used to further develop a mechanistic understanding of boiling in small channels and to improve heat transfer correlations. The test apparatus has been designed to utilize state-of-the-art ultra-high- 
speed digitized video-based flow visualization, together with long-range microscope optics, to study the microscale/time-resolved behavior of boiling-generated vapor bubbles.

\section{Test apparatus}

The test apparatus consists of a constant-temperature bath for controlling the temperature of the fluid entering the boiling channel, a variable-speed, positivedisplacement pump for regulating the flow in the channel, a DC electric power supply for controlling the heat flux to the heated wall of the channel, a light source for illuminating the flow channel, a boiling flow channel, an ultra-high-speed video camera with long-range microscope lens and video recorder electronics/monitor.

The flow channel contains three basic components. Two aluminum plates sandwich two window plates that in turn sandwich a Teflon flow channel sheet. A slot, and a circular flow plenum at each end of the slot, are machined in the Teflon sheet. Thickness of the Teflon corresponds to the dimension of the short side of the rectangular channel. The slot plus the two flow windows form the four sides of a horizontal 500-mm-long rectangular channel, with cross-sectional dimensions of $2.5 \times 6.0 \mathrm{~mm}$, in which boiling takes place. The boiling is produced by a thin electrically heated strip of stainless steel foil bonded to the bottom edge of the Teflon slot. The flow is observed and illuminated through the long sides of the channel using back lighting. Instrumentation such as pressure taps and thermocouples is located in small holes in the windows. By varying the thickness of the Teflon sheet and the width of the machined slot, rectangular geometries of various dimensions can be tested. Flow visualization data from the $2.5 \times 6.0 \mathrm{~mm}$ channel are presented in this paper.

The video camera and optics furnish the high picture rates and magnification needed to achieve temporal and spatial resolution of nucleate bubble growth and behavior in the channel. The video camera is a Kodak SP2000 Motion Analysis System. The camera is monochrome and is based on a CCD sensor comprising a $240 \times 192$ pixel array. Fullframe video images at up to $2000 \mathrm{pps}$ are viewed on a built-in 12 in. monitor. By dividing the video frame into $1 / 2,1 / 3$, or $1 / 6$ segments, the system is capable of speeds of 4000 , 6000 , and $12000 \mathrm{pps}$, respectively. All recorded images are capable of being digitized by system electronics for digital image analysis. An Infinity Model K2 Long-Range Microscope lens system is used. The lens has an effective aperture of $1.5 \mathrm{in}$. and furnishes variable working distances, magnification, field of view, and depth-of-field, depending on the primary and eyepiece lenses and the monitor size utilized. Magnification as high as $400 \mathrm{x}$ and $\mathrm{a}$ depth of field of a few millimeters are achievable.

\section{Results}

The channel cross-section size was chosen on the basis of nucleate bubble sizes predicted for water (Kasza and Wambsganss 1994). It was estimated that vapor bubbles would grow to about $3 \mathrm{~mm}$ in diameter at a nucleation site under the conditions of this test and hence would experience confinement by the channel walls. For these tests, water entered the channel slightly subcooled at nominally $1 \mathrm{~atm}$ pressure and was electrically heated on one of the channel short walls. High-speed video at $2000 \mathrm{pps}$ and microscope optics at 50x magnification were used to record nucleate vapor-bubble growth at the heated wall, bubble confinement by the channel walls, and bubble/bubble coalescence. The individual bubbles nucleated at the heated wall were nominally the same size as the channel cross section and developed into flow patterns and regimes considerably different from those generally occurring in large channels. 
In large channels, which have been studied extensively, it is generally agreed that when subcooled water enters a channel and is heated, a series of flow regimes evolves along the channel starting with single phase and followed by bubbly flow, plug flow, slug flow, wavy flow, and annular flow (depending on specific conditions, some of these may not occur). Figure 1 shows the Argonne-developed picture of the dominant regimes during nucleate boiling in a small horizontal channel. As depicted, the flow enters as a subcooled single phase and when the wall superheat reaches a threshold value a certain distance into the channel, the first nucleation site(s) grows a vapor bubble(s) that becomes nominally the same size as the channel cross section and then experiences confinement. Even if a single bubble does not grow at a wall nucleation site to a size where it experiences direct contact with the other walls, there is a wide range of conditions in which the wall superheat is high enough that the bubble generation frequency is sufficiently great that two or more

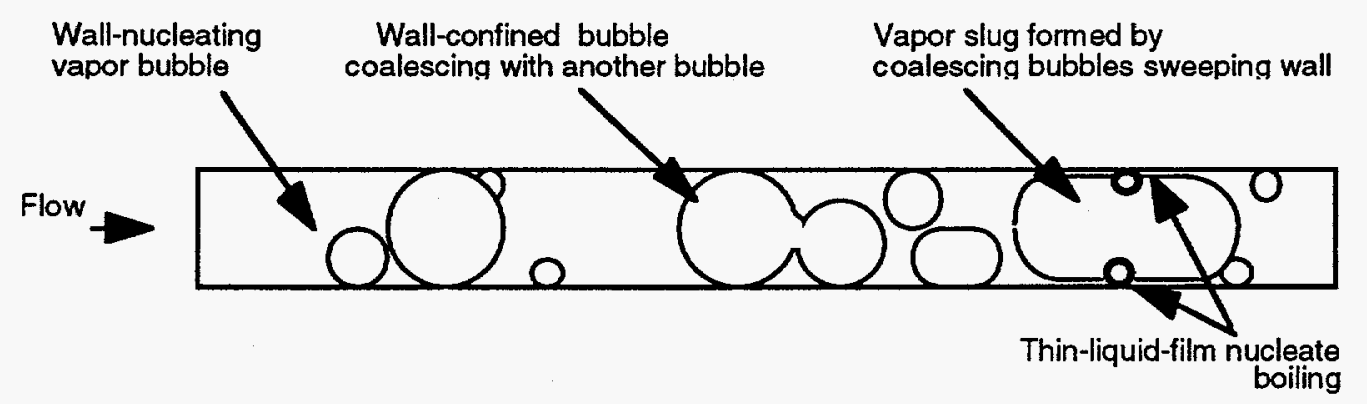

Fig. 1. Flow regimes during nucleate boiling in a horizontal small channel

successive bubbles from a given site or adjacent sites will coalesce to form a bubble large enough to experience channel confinement. Because the vapor bubbles are confined, they are forced to sweep the walls of the channel as they are conveyed down the channel by the forced flow. As a large vapor bubble sweeps by nucleation sites that are generating bubbles, it coalesces with them and thus increases the vaporization rate. If the wall superheat is large enough, large vapor slugs form, vapor resides in the core of the channel, and a thin liquid film coats the channel walls. The videos clearly show that under this condition a given nucleation site will continue to nucleate through the thin liquid layer.

Figure 2 shows a typical sequence of time-related video frames depicting vapor bubble growth and behavior in the channel. The test conditions are wall heat flux of 110 $\mathrm{kW} / \mathrm{m}^{2}$ and mass flux of $21 \mathrm{~kg} / \mathrm{m}^{2} \mathrm{~s}$. The time-averaged quality (vapor mass fraction) at the viewing location is estimated to be 0.15 . Field of view is approximately $6 \mathrm{~mm}$ top to bottom. The use of backlighting causes the short heated wall at the bottom of each frame to appear black. Furthermore, all liquid/vapor interfaces that are not flat and perpendicular to the light, as a result of light ray bending, also appear black. Hence the nearly spherical bubbles in various frames appear black with a "cats-eye" light region in their centers due to the absence of ray bending when the rays strike normal to the bubble/liquid interface. It should be noted that when a bubble is large enough to feel confinement by the transparent long walls of the channel, the cats-eye becomes larger because more rays pass through the bubble. This behavior is used to indicate when confinement occurs. Likewise, when a large vapor slug is formed, the thin liquid film on the viewing walls of the channel, if free of ripples, passes light through the channel and the vapor slug appears as a light zone surrounded by a dark band (i.e., the curved liquid/vapor interface). 


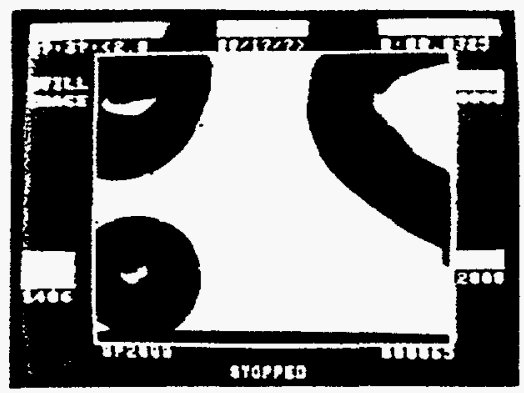

a

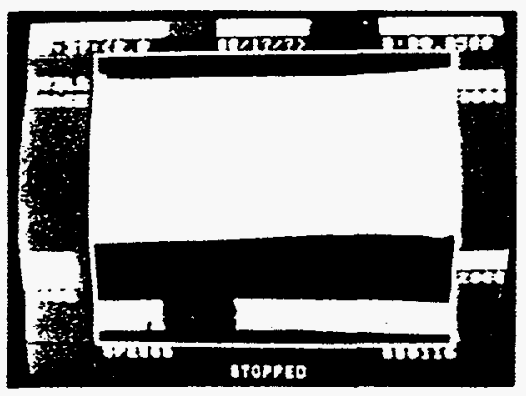

d

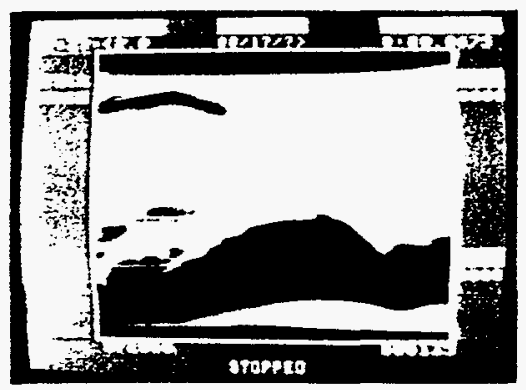

g

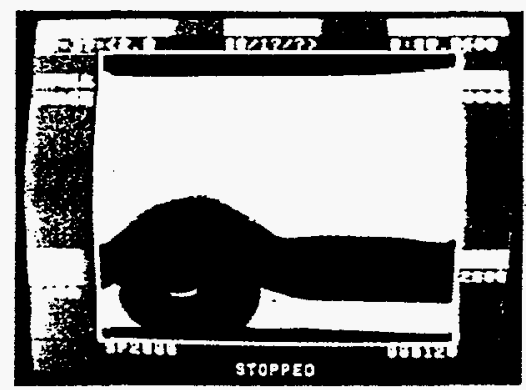

e

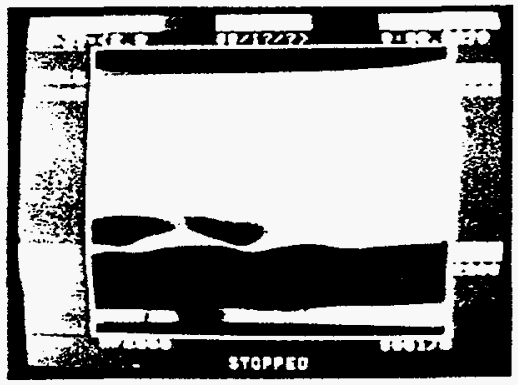

h

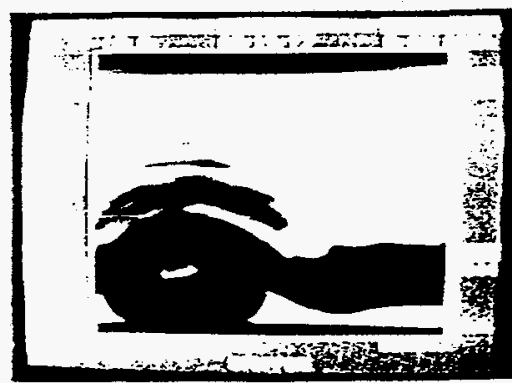

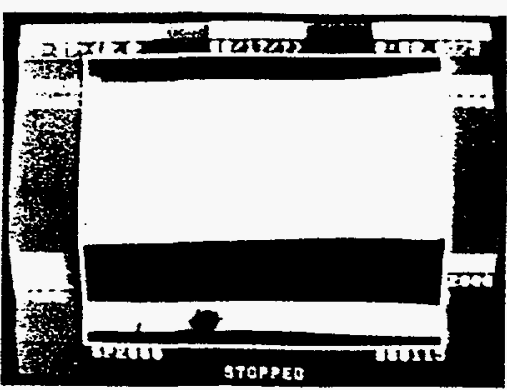

c

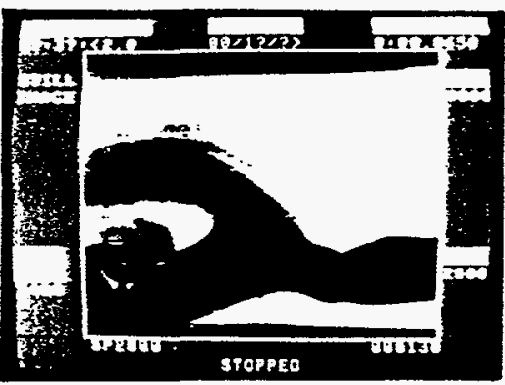

f

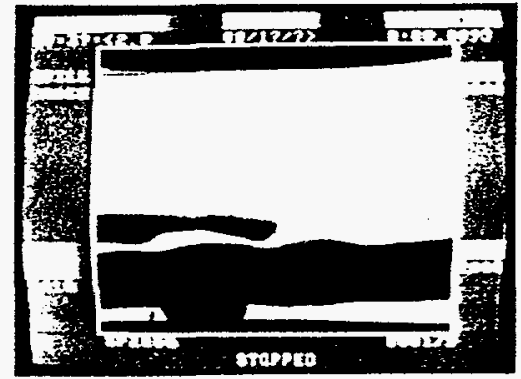

i

Fig. 2. Nucleate vapor bubble growth at heated short wall of a small rectangular channel, and interaction with a vapor slug resulting in thin-liquid-film boiling (flow right to left, $2000 \mathrm{pps}$ ) 
The video sequence depicts a vapor bubble nucleating at the heated wall and growing through the wall thin liquid layer (a-d) located between a large slug of vapor occupying the core of the channel and the wall, breaking through the wall-liquid/channel-core vapor interface to release its vapor to the core $(\mathrm{e}-\mathrm{g})$; the process is then repeated, at the same nucleation site $(\mathrm{h}-\mathrm{j})$. This entire process takes place in a few thousandths of a second. The phenomenon increases the nucleation-site bubble-generation frequency and enhances boiling heat transfer relative to that in large tubes. Furthermore, as shown in the video data, a bubble confined in a small tube and producing the very intense mixing of the channel flow because of the rapid bubble growth dynamics causes the nucleate boiling heat transfer characteristics to be exhibited over a much wider range of conditions than found in large tubes.

\section{Conclusions}

This paper will present highly detailed microscale time-resolved video data that support an improved understanding of the flow and boiling heat transfer regimes in small channels. Such flow visualization data are aiding in the development of criteria for designating when a boiling channel should be called large or small, as well as development of improved heat transfer correlations for advanced-design heat exchangers.

\section{References:}

Kasza, K. E., and Wambsganss, M. W., 1994, "Development of a Small-Channel Nucleate-Boiling Heat Transfer Correlation," Argonne National Laboratory Report ANL-94/32, June 1994.

Reay, D. A., 1988, "Impact of New Technologies on Future Heat Exchanger Design," Heat Recovery Systems and CHP 8(4), 309-314.

Shah, R. K., 1991, "Compact Heat Exchanger Technology and Applications," Compact Heat Exchanger Technology: Current Practice and Future Developments, Inst. Chemical Engineers, London, UK, 1-29.

Tran, T. N., Wambsganss, M. W., France, D. M., and Jendrzejczyk, J. A., 1993, "Boiling Heat Transfer in a Small, Horizontal, Rectangular Channel," Heat TransferAtlanta, AIChE Symp. Series 89(295), 253-261.

Wambsganss, M. W., France, D. M., Jendrzejczyk, J. A., and Tran, T. N., 1993, "Boiling Heat Transfer in a Horizontal Small-Diameter Tube," Trans. ASME, J. Heat Transfer 115, 963-972; also, Argonne National Laboratory Report ANL-92/12, 1992.

Wambsganss, M. W., and Shah, R. K., 1994, "Vaporization in Compact Heat Exchangers," presented at International Symposium/Workshop on Boiling, Condensation, and Two-Phase Heat Transfer, Andhra University, Visakhapatnam, India, January 10-11, 1994. 